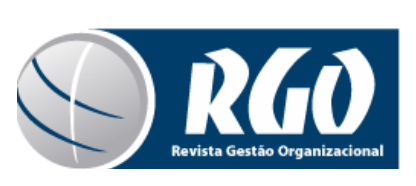

\title{
O ETARISMO NO LOCAL DE TRABALHO: EVIDÊNCIAS DE PRÁTICAS DE “SANEAMENTO” DE TRABALHADORES MAIS VELHOS
}

\section{THE AGEISM AT WORK PLACE: EVIDENCES OF "SANITATION" PRACTICES OF OLDER WORKERS}

\author{
DARCY MITIKO MORI HANASHIRO \\ Professora Titular na Universidade Presbiteriana Mackenzie \\ Docente do Programa de Pós-Graduação em Administração de Empresas \\ Orcid:0000-0003-2305-4186 / E-mail: darcyhanashiro@gmail.com \\ Endereço: Rua da Consolação, 896. Prédio 45, andar térreo. CEP 01302-907. São Paulo, SP. \\ MARIE FRANÇOISE MARGUERITE WINANDY MARTINS PEREIRA \\ Sócia da Acalântis - Executive Search \\ Mestre em Administração de Empresas \\ Orcid: 000000032217 950X / E-mail: fran@acalantis.com.br
}

\begin{abstract}
RESUMO
O Brasil assiste a uma mudança relevante na sua estrutura demográfica, resultando no envelhecimento populacional. Este fenômeno suscita nas organizações o desafio de reter e contratar pessoas mais velhas. Apesar de serem potenciais vítimas de discriminação etária, esses trabalhadores são pouco estudados. Assim, o objetivo deste artigo é compreender como o etarismo (ageism) se manifesta antes e depois do desligamento do último emprego, na ótica de gerentes desempregados. A pesquisa adota uma abordagem qualitativa baseada em 18 entrevistas face a face com gerentes acima de 45 anos. A análise dos dados foi apoiada nos passos descritos por Creswell (2014). Os resultados revelaram o corte de trabalhadores mais velhos como uma estratégia de "saneamento etário" nas organizações. Um prenúncio da demissão baseado em evidências sobre normas de idade, as consequências e justificativas sobre o corte são explicitadas na análise dos dados. Os resultados contribuem para um avanço na literatura, revelando como ocorre uma estratégia de renovação demográfica nas organizações sob o manto do corte, tomado como inevitável pelas organizações para sua sustentabilidade econômica.
\end{abstract}

Palavras-chave: Discriminação por idade. Demissão. Pessoas mais velhas.

\begin{abstract}
Brazil is undergoing a significant change in its demographic structure, resulting in population aging. This phenomenon raises the challenge of retaining and hiring older people in organizations. Although they are potential victims of age discrimination, these workers are little studied. Thus, this article aims to understand how ageism manifests itself before and after dismissal from the last job, in the view of unemployed managers. The research is characterized by a qualitative approach, through face-to-face interviews with 18 managers over 45 years old. Data analysis was based on the steps described by Creswell (2014). Results revealed the layoff of older workers as a strategy of "age sanitation" in the organization. A sign of the dismissal based on evidence on age norms, and the consequences and justification for the layoff are explicit in data analysis. The results contribute to advance literature, revealing how a strategy of demographic renewal occurs in organizations under the mantle of cutoffs, taken as inevitable for their economic sustainability.
\end{abstract}

Keywords: Age discrimination. Dismissal. Older people.

Data de submissão: 05/08/2019. Revisão: 17/04/2020. Data de aceite: 27/05/2020. Data de publicação: 05/06/2020. 


\section{INTRODUÇÃO}

O Brasil vive um novo paradigma demográfico, diante da diminuição do ritmo de crescimento da população e de mudanças na estrutura etária, tendo como perspectiva de futuro um declínio do contingente populacional a partir de 2035, e uma estrutura etária superenvelhecida (CAMARANO; KANSO; FERNANDES, 2014).

Apesar do crescimento da população de idosos no mundo, o etarismo (ageism) continua negligenciado como uma forma de discriminação (CARY; CHASTEEN; REMEDIOS, 2017). A discriminação voltada aos mais velhos, contudo, pode afetar um número crescente de pessoas, face ao envelhecimento da população (SWIFT et al., 2016). O etarismo no local de trabalho, em particular, continua a ser um problema mundial (MACDONALD; LEVY, 2016), na medida em que os estereótipos etaristas influenciam a percepção dos empregadores de trabalhadores mais velhos, que os consideram incompetentes, em razão do declínio das capacidades físicas e mentais, e difíceis de serem treinados (NELSON, 2016), o que contribui para a sua demissão. Por essas razões, a discriminação no local de trabalho em razão da idade tem uma importância crescente (TRUXILLO et al., 2018).

Como as pessoas vivem mais tempo e com mais saúde, também permanecem no mercado de trabalho por mais tempo e com maior probabilidade de serem vítimas de discriminação com base na idade. A discriminação com base na idade é generalizada, mas não amplamente reconhecida (MAGNARELLI et al., 2020). Ao contrário do racismo e do sexismo, a discriminação com base na idade é frequentemente normalizada (OMS, 2020).

Da mesma forma, são escassas as pesquisas brasileiras voltadas ao envelhecimento e à discriminação por idade no ambiente organizacional. A dimensão 'idade', concernente especialmente a trabalhadores mais velhos, tem sido um tema pouco discutido na área da Administração (LOCATELLI; FONTOURA, 2013). Nos Estados Unidos, Shore et al. (2009) confirmam a escassez de pesquisas sobre esse tema, embora Nelson (2016) já tenha observado um pequeno, mas rápido crescimento de estudos sobre etarismo. Nesta mesma linha de argumentação, North e Fiske (2012, p. 1) ressaltam que "seja qual for a razão, o preconceito baseado na idade permanece sendo drasticamente subinvestigado, apesar da saliência da idade nos julgamentos interpessoais". Uma das possíveis razões apontadas por Nelson (2009) é a institucionalização do etarismo em sociedades como a estadunidense, fato que contribui para a naturalização do fenômeno. Assim, as pessoas entendem que não há nada de errado em serem caracterizados a partir dos estereótipos etários.

Pesquisas realizadas no Brasil mostram a falta de práticas e políticas direcionadas aos trabalhadores mais velhos. Cepellos et al. (2013) pesquisaram 138 gestores de Recursos Humanos e concluíram que, de modo geral, eles têm uma percepção positiva sobre os profissionais mais velhos, acima de 50 anos de idade. No entanto, tais atitudes não resultaram na adoção de práticas de Recursos Humanos voltadas à gestão da idade nas organizações pesquisadas. Resultados similares foram encontrados em uma pesquisa realizada pela FGV/EAESP (TONELLI; CEPELLOS; LINS, 2018), com uma amostra formada por 140 gestores de empresas de vários setores. Nessa mesma vertente, Amorim, Fevorini e Melo Alves (2016) confirmam a baixa preocupação das organizações no Brasil com o envelhecimento.

No âmbito da sociedade, aumentam os desafios a serem enfrentados pelos trabalhadores. A proposta em curso, de revisão do atual sistema de aposentadoria no Brasil, prolonga a vida laboral, ao contrário da aposentadoria precoce estimulada pelo sistema previdenciário vigente. Tendo que se manter por mais tempo em atividade produtiva, esses trabalhadores tendem a facejar a hostil ocorrência da discriminação por idade, notória no contexto das organizações, como evidenciado em pesquisas empíricas. A discriminação por

RGO - Revista Gestão Organizacional, Chapecó, v. 13, n. 2, p. 188-206, maio/ago. 2020. 
idade pode trazer consequências danosas à carreira de um profissional, uma vez que a idade norteia o modo como as relações humanas são estruturadas e valorizadas nas organizações (FINEMAN, 2014). Estudos apontam que profissionais mais velhos estão sujeitos a enfrentar obstáculos nos diferentes processos de gestão de pessoas (PERRY; PARLAMIS, 2006; TRUXILLO et al., 2018). Além disso, os trabalhadores mais velhos são as primeiras vítimas da reestruturação do emprego e dos regulamentos relativos aos limites de idade durante o recrutamento (KIM; MO, 2014). A confluência desses fatores mencionados sugere que é vital avançar no entendimento sobre o etarismo no ambiente de trabalho, pois as consequências vão além da esfera individual, impactando a sociedade como um todo. Logo, a discriminação etária é um tema de relevância incontestável a ser explorado, com vistas a contribuir para o avanço da literatura, sobretudo fundamentada em experiências brasileiras.

Diante de um panorama em que evidências empíricas apontam para a existência de discriminação por idade nas organizações (POSTHUMA; CAMPION, 2009; POSTHUMA; WAGSTAFF, CAMPION, 2012) e da importante lacuna que ainda se verifica nas pesquisas acadêmicas correntes, este artigo tem como objetivo compreender como o etarismo se manifesta antes e depois do desligamento do último emprego, na ótica de gerentes desempregados com idade acima de 45 anos. O critério para a escolha dessa faixa etária tem como sustentação a declaração da Organização Mundial de Saúde (OMS, 2015), de que o processo de envelhecimento funcional se inicia em torno dos 45 anos de idade.

Este artigo está estruturado em quatro tópicos, além desta introdução. 0 primeiro aborda o fenômeno do envelhecimento no Brasil, os estereótipos, o preconceito e a discriminação etária, o conceito de etarismo e as normas de idade nas organizações. Em seguida, explicita-se o percurso metodológico, e no terceiro tópico são apresentados os resultados e a discussão. Por último, destacam-se as considerações finais, com as contribuições para a literatura, as implicações sociais e para as organizações, as limitações do estudo e uma agenda para pesquisas futuras.

\section{REFERENCIAL TEÓRICO}

O envelhecimento da população é uma realidade universal que está ocorrendo em todas as regiões do mundo, progredindo mais rapidamente nos países em desenvolvimento (FUNDO DE POPULAÇÃO DAS NAÇÕES UNIDAS, UNFPA, 2012). O Relatório do Banco Mundial aponta que a velocidade do envelhecimento populacional no Brasil será significativamente maior do que ocorreu nas sociedades mais desenvolvidas no século passado. O Brasil encontra-se diante de uma transição demográfica, processo caracterizado por baixa fecundidade, baixa mortalidade e preponderância de idosos (BANCO MUNDIAL, 2011). Essa mudança vem se acentuando drasticamdente nas últimas décadas, de forma que, a partir de 2020, o Brasil perderá o chamado bônus demográfico, significando que o percentual da População em Idade Ativa (população de 15 anos ou mais) começará a decrescer em relação à população dependente (menores de 15 e maiores de 65 anos). A partir de 2030, a proporção da população de idosos será superior à população abaixo de 15 anos (INSTITUTO BRASILEIRO DE GEOGRAFIA E ESTATÍsTICA, 2013).

Este novo paradigma demográfico, associado às consequências das mudanças no sistema previdenciário brasileiro, impele as organizações a enfrentarem um duplo desafio, em um futuro próximo: a necessidade de reter empregados mais velhos em seus quadros e a lidar com a pressão de contratar pessoas mais velhas, produtivas e capacitadas, que precisam continuar ativas no mercado de trabalho. Paradoxalmente a essa realidade inexorável do aumento da população de trabalhadores mais velhos, um corpo crescente da literatura revela 
a persistência de preconceito etário, com consequências diretas na exclusão laboral. Nessa linha de pensamento, argumenta-se que o aumento de sociedades centradas na juventude traz crescente preocupação sobre como a idade e o envelhecimento podem afetar o local de trabalho (MACDONALD; LEVY, 2016), o que justifica estudos sobre etarismo desenvolvidos a partir da realidade brasileira, até agora escassos.

\subsection{O ETARISMO NO AMBIENTE DE TRABALHO}

No Brasil, o termo etarismo não é consagrado como na literatura internacional (ageism). Encontram-se distintas designações como ageísmo, edaísmo ou idadismo. Os termos etarismo e idadismo constam no dicionário da língua portuguesa Priberam. Etarismo é composto pelo adjetivo etário (relativo a, ou próprio da idade) + o sufixo -ismo. Em vista desta etimologia, doravante será utilizado o termo etarismo para designar ageism.

O termo etarismo foi introduzido por Butler, um dos pioneiros na pesquisa de envelhecimento. Butler usou a palavra ageism para descrever "preconceito por um grupo de idade contra outro grupo de idade" (BUTLER, 1969, p. 243) e o chamou de outra forma de intolerância (bigotry), similar a racismo e sexismo. Posteriormente, o autor definiu o etarismo como "um processo sistemático de estereótipos e discriminação contra pessoas porque elas são mais velhas" (BUTLER, 1975, p. 12). Em trabalho subsequente, Butler (1980) identifica três aspectos do problema do etarismo: atitudes preconceituosas; práticas discriminatórias contra os idosos; e práticas e políticas institucionais que perpetuam crenças estereotipadas sobre os idosos, e deterioram sua dignidade pessoal. Desde então, uma vasta gama de evidências tem presença frequente em estudos sobre a discriminação baseada na idade. Butler (1980) argumenta que as atitudes e as crenças, os comportamentos discriminatórios, as normas e as políticas institucionais estão relacionadas e se reforçam mutuamente.

Nem sempre, contudo, o etarismo está associado somente a pessoas mais velhas, e com conotação negativa. Palmore $(1999$, p. 4) define etarismo como "qualquer preconceito ou discriminação contra ou a favor de um grupo de idade". Contudo, a maioria dos autores refere-se ao aspecto negativo. $O$ etarismo manifesta-se tanto no âmbito pessoal como no institucional (PALMORE, 1999). O etarismo pessoal refere-se ao preconceito e discriminação preconizados por indivíduos, enquanto o institucional diz respeito à prática de uma instituição ou organização, por meio de suas rotinas e políticas. Assim, o etarismo aparece de forma sutil ou marcante em diversas situações.

O escopo do etarismo aparece também na pesquisa realizada por Stypinska e Turek (2017). A discriminação por idade no ambiente de trabalho pode assumir uma forma dual: rígida (hard) e suave (soft). A forma rígida espelha os tipos de comportamentos legalmente proibidos e aqueles relacionados às decisões reais dos empregadores que podem afetar a carreira do funcionário. Por outro lado, a discriminação suave corresponde àquelas ocorrências que não estão inscritas no sistema legal per se, que ocorrem predominantemente na esfera interpessoal, mas podem ter consequências negativas para os trabalhadores mais velhos.

O envelhecimento crescente da população tende à intensificação do etarismo, evidenciado na concepção de Bytheway (1995, p. 14) como "um conjunto de crenças originadas na variação biológica entre as pessoas, e relativas aos processos de envelhecimento". Nelson (2004) sintetiza o etarismo como estereótipos e preconceitos contra pessoas mais velhas. A par da constatação de Ayalon e Tesch-Römer (2018), de que não há consenso em relação ao conceito de etarismo e suas causas, defendemos que o etarismo se 
refere aos estereótipos, preconceitos e discriminação, com base somente na idade cronológica, direcionados às pessoas mais velhas.

O estereótipo etário descreve crenças e expectativas compartilhadas sobre trabalhadores e seu comportamento, baseadas na idade cronológica ou idade percebida (POSTHUMA, WAGSTAFF; CAMPION, 2012). Os estereótipos, por atuarem como expectativas que guiam o processamento de informação sobre o grupo como um todo, e sobre membros particulares desse grupo, direcionam o nosso comportamento, com impacto pernicioso para as pessoas, pois permitem inferir uma característica baseada na afiliação do grupo. Estereótipos são traços que vêm rapidamente à mente quando pensamos em determinados grupos sociais, e são problemáticos porque são negativos, imprecisos e injustos (NELSON, 2009). Podem basear-se em boatos, ideias preconcebidas ou suposições infundadas, e levar à inferência incorreta de que todos os membros desse grupo são iguais (FISKE; TAYLOR, 1991). $O$ estereótipo é a base para o preconceito e a discriminação no ambiente de trabalho. $O$ preconceito é definido como uma atitude negativa em relação a um grupo ou membros desse grupo (NELSON, 2009), portanto é mais afetivo, e diferente da discriminação, que é de natureza comportamental (FISKE, 2004; NELSON, 2004).

Posthuma, Wagstaff e Campion e (2012) categorizaram vários tipos de estereótipos de idade prevalentes no local de trabalho. A maioria é de estereótipos negativos, e alguns são refutados por evidências empíricas. Poucos dizem respeito a estereótipos positivos em relação ao trabalhador mais velho. Os autores revelam que os estereótipos negativos recorrentes na literatura referem-se ao baixo desempenho dos trabalhadores mais velhos: resistência à mudança; baixa habilidade para aprender; pouco tempo remanescente de empresa e, portanto, menor retorno sobre investimento em treinamento; custo mais elevado para as empresas; classificação mais baixa em entrevistas; e avaliações de desempenho. Contudo, Posthuma, Wagstaff e Campion (2012) argumentam que há poucas evidências empíricas de que o desempenho no trabalho decline à medida que o trabalhador envelhece, e sua idade é menos importante para o desempenho do que suas habilidades individuais e a saúde. Refutando o argumento sobre o pouco tempo remanescente na empresa, a literatura mostra que, em geral, o retorno do investimento em treinamento aplicado aos trabalhadores mais velhos não é baixo, pois a probabilidade de eles deixarem a empresa é menor.

Por outro lado, a literatura sugere estereótipos positivos: os trabalhadores mais velhos são mais estáveis, confiáveis, honestos, leais e comprometidos com o trabalho, menos propensos a perder o trabalho e, ainda, têm menor rotatividade (POSTHUMA; CAMPION, 2009). North e Fiske (2012, p. 4) apontam que tem havido um aumento de pesquisas sobre os benefícios do envelhecimento do trabalhador, em oposição aos estudos que realçam apenas suas desvantagens. Numerosos pesquisadores têm testado a noção de que "older is wiser". Entretanto, os autores constatam que, não obstante esses achados positivos, as "crenças exageradas sobre anciãos tristes, frágeis e solitários persistem, do nível interpessoal ao social".

Goldani (2010) argumenta que o preconceito etário e a prática da discriminação por idade deveriam ser vistos como parte das múltiplas formas de discriminação experimentadas pelos indivíduos, ou seja, não apenas os tradicionais "ismos", como sexismo e racismo. Mesmo porque o etarismo é implacável com todos que viveram o suficiente para serem considerados idosos. Alguns estudos brasileiros têm revelado a existência do etarismo nas organizações, principalmente no processo seletivo (PEREIRA, 2014). Profissionais mais velhos deixam de ser contratados ou promovidos porque os chefes acreditam que sejam menos flexíveis e competentes do que os mais jovens (GOLDANI, 2010). 
Em estudo com 138 profissionais brasileiros de RH, Cepellos et al. (2013) concluíram que, embora os gestores acreditem que os mais velhos apresentam atributos positivos, como produtividade, confiabilidade, comprometimento e pontualidade, na maioria das vezes, as empresas não possuem uma postura proativa na contratação de profissionais maduros ou que estão próximos da idade de se aposentar. Para os autores, a acomodação, falta de atualização, altos salários, limitações físicas, limitações mentais e dificuldades em aceitar líderes mais jovens são as principais barreiras para se compor equipes com profissionais mais velhos. Vasconcelos (2016) considera que a crença no declínio da capacidade de aprendizado das pessoas mais velhas consiste em um dos vieses mais frequentes, presentes nas práticas e políticas de gestão. Esse viés etarista pode ser tão sutil que as pessoas podem não perceber como eles se incorporam às atitudes e comportamentos nas organizações, funcionando como normas de conduta compartilhadas pelos membros de um determinado grupo ocupacional em relação à idade. Uma pesquisa nacional com trabalhadores de todas as regiões do Brasil, realizada por França et al. (2017), evidenciou que mulheres e trabalhadores mais velhos apresentaram atitudes mais positivas frente ao envelhecimento, enquanto trabalhadores mais jovens e com menor escolaridade demonstraram atitudes mais negativas com relação ao envelhecimento no ambiente organizacional.

Os estereótipos mencionados anteriormente podem engendrar efeito deletério para os trabalhadores mais velhos. Por essa ótica, se os gerentes possuem esses estereótipos, ainda que sejam sutis e inconscientes, isso afeta seu modo de pensar sobre os trabalhadores mais velhos (POSTHUMA; CAMPION, 2009, p. 160). Consequentemente, afirmam os autores, o resultado pode ser uma discriminação contra esses trabalhadores, "na medida em que estes não são contratados, selecionados para treinamento, ou se tornam alvo de demissão". Quando amplamente compartilhados, os estereótipos sobre idade podem se configurar como uma norma social do comportamento esperado nas organizações.

\subsection{NORMAS DE IDADE}

Assim como o gênero, a idade é fator de distinção entre os indivíduos e submete as pessoas às normas sociais, moldando a conduta das atividades dos seres humanos. Os mitos sobre idade são tenazes, especialmente quando existe um autointeresse incorporado em preservar uma equipe de trabalhadores mais baratos e mais novos (FINEMAN, 2014). Por esse raciocínio, o emprego autônomo pode contornar algumas dessas dificuldades, evidenciadas pelo crescimento dos "empresários mais velhos" (olderpreneurs) - novos negócios entre os profissionais com idade superior a 50 anos (FINEMAN, 2014, p. 1721).

Nas organizações, o conceito de idade é igualmente importante, e pode ser analisado por meio de sua distribuição etária, ou o número de empregados de cada idade em determinada posição ou ocupação na empresa (LAWRENCE, 2004). Essa demografia pode revelar aspectos do etarismo institucional.

A idade é um fato imutável da vida e significa algo diferente para pessoas em distintas organizações, ocupações e indústrias (LAWRENCE, 2004). A idade influencia o comportamento, e o resultado do efeito da idade é que alguns problemas de emprego relacionados a ela são, na realidade, criados pelas organizações. Assim, ser considerado um trabalhador mais velho vai além de um critério racional e universal, mas depende do entendimento compartilhado existente na organização, sobre o significado do que é ser mais velho.

As organizações definem e são definidas pela idade de seus empregados (LAWRENCE, 2004). Os efeitos invariantes da idade têm sido objeto de estudo de pesquisadores, e mostram 
dupla direção. De um lado, eles recomendam que as organizações se adaptem às necessidades relativas à idade dos trabalhadores. Por outro, é fato que os empregados precisam se adaptar às definições de idade de suas organizações. Ou seja, existem normas de idade que direcionam o comportamento organizacional. Para Lawrence (2004, p. 991), normas de idade são "crenças compartilhadas sobre idades típicas de indivíduos dentro de uma dada posição, e os significados compartilhados que aquelas crenças geram dentro de uma ocupação ou organização". A autora cita que, nas organizações, a norma de idade mais comum é aquela que os empregados desenvolvem em torno do progresso de carreira e posição. Em geral, as normas de idade refletem estereótipos etários e podem estar incorporadas nas práticas organizacionais, revelando julgamentos sobre a adequação de candidatos para determinada vaga, ou até expectativas sobre o desempenho de pessoas nas diferentes idades e fases de sua carreira. Existe, por vezes, a percepção de que certos empregos ou mesmo profissões devem ser ocupados por empregados de uma certa faixa etária (POSTHUMA; CAMPION, 2009). Além disso, os achados de Karpinska et al. (2013) mostram que as normas de idade dificultam o retorno de aposentados precoces à força de trabalho, mostrando o amplo efeito dessas normas.

Os estereótipos e normas de idade operam para que trabalhadores mais velhos enfrentem uma barreira: o teto grisalho. Esse limite ocorre quando as carreiras se estabilizam e suas habilidades se tornam obsoletas ou ultrapassadas, sendo então considerados muito velhos e inflexíveis para aprender novas habilidades e acompanhar as demandas da organização (THOMAS et al., 2014). Uma barreira adicional é enfrentada pelas mulheres, que confrontam um duplo risco: frequentemente elas experienciam a discriminação por idade mais cedo do que os homens (FINEMAN, 2014).

\section{PERCURSO METOdOLÓGICO}

A estratégia de pesquisa qualitativa (CRESWELL, 2014) adotada neste estudo mostrase apropriada para o entendimento mais profundo do fenômeno investigado. Esse autor sintetiza algumas características da pesquisa qualitativa, que balizaram a presente investigação: a pesquisa qualitativa ocorre em um cenário natural, é emergente em vez de estritamente pré-configurada, e é fundamentalmente interpretativa. O pesquisador qualitativo vê os fenômenos sociais holisticamente e usa processos indutivos e dedutivos na análise dos dados.

Os participantes da pesquisa foram "propositalmente selecionados" (CRESWELL, 2014, p. 239) para o estudo, com o objetivo de entender o problema de pesquisa, e a forma de acesso foi baseada na rede de relacionamentos profissionais dos pesquisadores. A saturação de conteúdo definiu o número de entrevistados, e ocorreu em torno da 17a e 18a entrevistas.

Para complementar, adotou-se os quatro aspectos identificados por Miles, Huberman e Saldaña (2014): 1) o cenário - a pesquisa ocorreu em local definido pelos participantes na cidade de São Paulo; 2) os atores foram gerentes, homens e mulheres, desempregados por iniciativa própria ou da empresa, com trajetória em organizações privadas, em qualquer área de atuação e idade acima de 45 anos. 0 interesse por profissionais de nível gerencial deve-se ao fato de estes, potencialmente, exercerem um duplo papel, tanto como eventual vítima de uma discriminação por idade quanto um agente dessa prática, no exercício cotidiano de sua função gerencial. O nível gerencial refere-se à hierarquia intermediária, posicionada entre a direção e as chefias nas organizações. Foram considerados os profissionais que haviam deixado a empresa no período de dois meses a um ano antes da entrevista. Esse hiato foi definido para que o tempo de demissão não fosse excessivamente curto ou longo, a ponto de

RGO - Revista Gestão Organizacional, Chapecó, v. 13, n. 2, p. 188-206, maio/ago. 2020. 
interferir nos relatos; 3) o evento central da pesquisa retratado pelos participantes foi a demissão; 4) o processo consistiu em entender a natureza evolutiva do evento, antes e depois da demissão vivenciada pelos participantes.

As entrevistas foram realizadas face a face, com duração média de 80 minutos, conduzidas por um roteiro semi-estruturado, com algumas perguntas abertas a fim de extrair visões e experiências dos participantes. Todas foram gravadas com permissão. A análise dos dados foi apoiada nos passos genéricos descritos por Creswell (2014): 1) organizar e preparar os dados, que consistiu na transcrição padronizada das entrevistas; 2) fazer leitura da transcrição para extrair o sentido do todo e as ideias gerais; 3) começar a análise detalhada com um processo de codificação, que envolve a separação de fragmentos de textos com núcleo de sentido, e a codificação desses segmentos; 4) usar o processo de codificação para gerar uma descrição do cenário ou das pessoas, além das categorias ou dos temas para análise; 5) prever como a descrição e os temas seriam representados. No caso desta pesquisa, usamos uma figura para representar o etarismo no processo de demissão, na ótica dos participantes (Figura 1); 6) fazer uma interpretação ou extrair significado dos dados. A análise dos dados foi intercalada com o uso de citações longas, curtas, separadas ou entremeadas no texto, juntamente com as interpretações dos autores do artigo, conforme sugestão de Creswell. A coleta dos dados e o processo de análise ocorreram simultaneamente, entendimento recorrente na pesquisa qualitativa.

\section{ANÁLISE E DISCUSSÃO DOS RESULTADOS}

Do total de 18 entrevistados (R1 a R18), havia dez mulheres e oito homens, na faixa etária de 45 a 68 anos. Todos possuíam formação acadêmica superior completa, 13 dos quais com pós-graduação. Com relação à área de atuação, cinco respondentes eram da área Financeira, quatro da área Comercial, três de Recursos Humanos, três da área Técnica, dois da Administrativa, e um da área de Logística.

A análise dos dados aborda duas categorias geradas pelo processo analítico: a) Composição Etária do Grupo de Trabalho e o prenúncio do desligamento; b) Ruptura pelo corte.

\subsection{A COMPOSIÇÃO ETÁRIA E O PRENÚNCIO DO DESLIGAMENTO}

A composição etária do grupo de trabalho diz respeito à faixa etária dos subordinados, pares e chefia do sujeito. Por meio desta análise, procuramos identificar como o respondente experienciou preconceitos e discriminações oriundos dessas relações intergrupais no seu cotidiano de trabalho.

Todos os participantes da pesquisa eram os mais velhos da sua equipe de trabalho e entre seus pares de diferentes funções. Em relação à chefia, três homens eram mais jovens que os chefes (R3, R5 e R8), e os demais sujeitos, mais velhos que eles. A média etária dos participantes estava em torno de $49-50$ anos. Inferimos que, por serem os trabalhadores mais velhos, já deveriam se perceber como dissimilares e constituintes de um grupo minoritário, o dos mais velhos. E, em razão dessa demografia etária pouco confortável, por não participarem do grupo de maioria, poderiam sofrer alguns estereótipos frequentemente atribuídos aos trabalhadores mais velhos (BYTHEWAY, 1995). Também esse dado revela a existência de uma norma de idade nas organizações onde atuavam esses gerentes, implícita ou explícita, que denota certa valorização de trabalhadores mais jovens, típica de sociedades cada vez mais centradas na juventude (MACDONALD; LEVY, 2016), inclusive no nível gerencial. 
Esta situação poderia ser o prenúncio de uma futura demissão. Vários profissionais mencionaram que tomaram conhecimento, após a demissão, de que suas funções foram atribuídas a profissionais mais jovens. A percepção sobre a demissão e seu contexto não é neutra em relação ao gênero, sendo que homens e mulheres a percebem de forma diferente (FINEMAN, 2014).

\subsubsection{A ótica masculina}

O entrevistado R1 (área Comercial) era cerca de dez anos mais velho que seus pares e seu superior. Assim como R4 (Gerente Financeiro), cuja equipe era formada por profissionais bem mais jovens do que ele. A demissão por corte atingiu profissionais que, como eles, eram mais velhos e tinham mais tempo de empresa. Ambos compartilharam algumas dificuldades em função de estereótipos relacionados às normas de idade das empresas onde atuaram. R1 relata que "(...) para uma gerência júnior eles querem alguém de até 30,35 anos (...) e quando você oferece uma supervisão júnior, normalmente o gestor ou o RH da outra divisão diz: não, não, a gente quer alguém mais novo pra posição". O gerente R4, por sua vez, explicita claramente que "parece que já tem uma convenção implícita: analista não pode ser maior de 30 anos, por exemplo (...) a gente não trazia ninguém com mais de 40 anos!". Evidências dessa natureza são expostas por Truxillo et al., 2018. Eles ponderam que certos cargos, profissões ou indústrias são tipificadas como jovens ou velhas, revelando estereótipos de trabalho relacionados à idade. Esses achados confirmam um dos argumentos teóricos de Lawrence (2004), de que as organizações definem a idade de seus trabalhadores, mas não encontramos nenhuma evidência empírica de que elas também se adaptam à idade dos empregados, como postulado por esta autora.

Para alguns entrevistados, uma das principais barreiras que acompanham os estereótipos etários negativos por parte dos empregadores é o custo financeiro mais elevado para as organizações. R3 afirma que a dona da empresa onde trabalhava não contratava pessoas com mais de 40 anos, pois dizia que "o cara não ia ter pique ou que ia encarecer o convênio médico com dependentes, essas coisas!". Nessa linha de raciocínio, os gerentes R4, R5 e R6 observaram que os salários mais elevados dos trabalhadores mais velhos foram determinantes para a demissão. R15 testemunhou essa situação e sua substituição por alguém mais novo, ao afirmar que foi escolhido "por ter o salário mais alto, e ficaram com o meu funcionário". Posthuma e Campion (2009) refutam o estereótipo de que trabalhadores mais velhos custam mais porque usam mais benefícios e estão mais próximos à aposentadoria. Os autores argumentam que faltam evidências para essas constatações. Por outro lado, os trabalhadores mais velhos têm maior comprometimento que os mais novos (FINEMAN, 2014).

Os depoimentos mostram que os trabalhadores mais velhos são constrangidos pelas normas de idade, e há uma percepção de que eles tendem a ser considerados como um recurso material a ser gerenciado, em que a ótica financeira torna-se um importante critério de decisão para demissões. Fineman (2014, p. 172) lembra que "os mitos etaristas são tenazes, especialmente quando o autointeresse corporativo assenta-se em preservar um time de trabalhadores mais baratos e jovens". Em contextos organizacionais em que o lucro é fator central das decisões, os empresários "costumam optar por substituir funcionários mais velhos, mais experientes e mais bem pagos, por uma mão de obra mais barata e jovem" (GOLDANI, 2010).

A ação anteriormente mencionada, voltada à substituição de profissionais mais velhos por outros mais jovens em cargos executivos, evidencia o etarismo institucional (PALMORE, 
1999). Na medida em que o etarismo se institucionaliza na organização, ele se manifesta em práticas informais. Tais fatos, paulatinamente, podem se transformar em normas de idade, conforme grupos de trabalho passem a compartilhar estereótipos negativos. $O$ estereótipo etário descreve crenças e expectativas compartilhadas sobre trabalhadores (POSTHUMA, WAGSTAFF; CAMPION, 2012). Em geral, são imprecisos e injustos (NELSON, 2009) e podem basear-se em boatos, ideias preconcebidas ou suposições infundadas, e levar à inferência incorreta de que todos os membros desse grupo são iguais (FISKE; TAYLOR, 1991). Logo, são perniciosos pois podem conduzir um gestor a uma decisão baseada preponderantemente em crenças generalizadas sobre trabalhadores mais velhos, tratando-os como um grupo homogêneo. As normas direcionam ações em relação a um objeto focal, como pode ser observado pelo relato de R6, que passou a ter chefias cada vez mais jovens, e de R9, que testemunhou passivamente o seu próprio processo de envelhecimento, que, por ser natural, não suscitou uma ação proativa e preventiva de sua parte, dentro do contexto organizacional.

\subsubsection{A ótica feminina}

Além dos estereótipos e preconceitos sexistas, amplamente documentados na literatura, as mulheres mais velhas também precisam lidar com o preconceito de idade (PALMORE, 1999; FINEMAN, 2014; NELSON, 2016). Uma discriminação múltipla, intensificada pela interseccionalidade idade/gênero, foi percebida por algumas das dez gestoras entrevistadas. As gestoras R2, R10, R13, R16 e R18 têm idade entre 47 e 55 anos, quatro atuam em áreas de suporte e uma na área comercial. Todas eram mais velhas que seus pares e equipes, e foram desligadas em função de corte nas empresas em que atuavam. As gestoras R8, R11, R12, R14 e R17 têm idade entre 45 e 52 anos, três trabalharam em áreas de suporte e duas na área técnica do setor farmacêutico. Elas eram todas mais velhas que suas equipes, mas não que seus pares ou superiores.

Em seu último emprego, R2 tinha uma equipe formada por profissionais jovens e acredita que suas dificuldades profissionais começaram quando fez 50 anos e a empresa em que trabalhava optou por demiti-la, permanecendo com os seus dois coordenadores, mais jovens que ela. Após muitas dificuldades para conseguir um novo emprego, aceitou uma proposta num cargo não gerencial, com salário inferior e em uma localidade afastada, no interior do Estado de São Paulo, tendo levado mais de um ano para conseguir de volta um cargo gerencial. No relato de R2, depreende-se que foi alvo de discriminação, fruto de estereótipos etários baseados na idade cronológica ou percebida, como já foi apontado por Posthuma, Wagstaff e Campion (2012).

A gestora R16 era a única mulher no nível gerencial e a mais velha entre seus pares, e isso lhe propiciava um tratamento diferenciado. Apesar de um clima de camaradagem em relação a ela no seu grupo de trabalho, os estereótipos etários e de gênero não deixavam de se manifestar. De um lado, pela defesa de uma forma de realização do trabalho consagrada pela sua experiência - "Alguns deles queriam fazer umas coisas que eu sabia que não iam dar certo, e a gente acabava discutindo muito ... eles me achavam meio antiquada em algumas coisas". Por outro lado, um estereótipo sutil manifestado em brincadeira - "Para com isso! Você tá ficando velha!". Inferimos que os colegas de R16 percebiam uma certa resistência à mudança e baixa habilidade para aprender, estereótipos prevalentes na literatura (POSTHUMA, CAMPION, 2009). A crença no declínio da capacidade de aprendizado dos trabalhadores mais velhos consiste em um dos vieses mais frequentes, presentes nas práticas e políticas de gestão (VASCONCELOS, 2016).

RGO - Revista Gestão Organizacional, Chapecó, v. 13, n. 2, p. 188-206, maio/ago. 2020. 
O preconceito de idade raramente opera de forma isolada (FINEMAN, 2011). Em geral, ele atua de forma cruzada com outro preconceito, como raça, gênero ou classe social. No caso da mulher, esse preconceito ocorre em diversas fases da vida e atrapalha os avanços de sua trajetória na organização (FINEMAN, 2011), como foi observado nas profissionais maduras e experientes da pesquisa.

Os relatos de R10 e R13, ambas sem vínculo formal de emprego, remetem a várias dificuldades ao longo de suas trajetórias, aspectos reforçados por R16. A gestora R13 relatou que desde os 42 anos só consegue trabalhos sem vínculo empregatício: "Depois dos 42 eu virei PJ [pessoa jurídica]: acabaram os benefícios! (...) a maior parte dos meus colegas de trabalho, nos últimos anos, estão perto dos 50 e estão passando por isso!"

Algumas respondentes apontam uma múltipla discriminação, provocada pelo fator idade e por ser mulher, sofrendo a concorrência de profissionais homens mais jovens, além das normas de idade implícitas no comportamento dos gestores. A gestora R11 constata que "porque a maioria dos donos de empresa são homens e eles terminam dando preferência para profissionais, gestores, do sexo masculino". Este depoimento reforça a lógica do paradigma da atração por similaridade (BYRNE, 1971). Além da preferência dos homens, anteriormente mencionada, R13 aponta a existência de sexismo nas organizações ao declarar que "as empresas são muito machistas! Por mais que você seja competente, o fato de ser mulher te tira pontos!". Uma justificativa financeira também foi um argumento utilizado pelo gestor de R18: "O meu diretor me chamou, do nada, e me disse que a empresa estava com problemas, que meu salário era um dos mais altos da gerência, e que iam ter que me cortar".

Esses achados confirmam um estereótipo negativo amplamente aceito, de que os trabalhadores mais velhos são mais caros; porém, há poucas evidências sobre a validade deste estereótipo (POSTHUMA et al., 2012). No contexto das organizações brasileiras, a pesquisa conduzida pela PwC/FGV (2013) demonstra que em apenas 32\% das empresas a exigência de salários mais elevados é uma barreira para contratação dos mais velhos, e $89 \%$ reconhecem que estes são mais fiéis, o que reduz os custos com turnover.

A gestora R14 (Gerente de $\mathrm{RH}$ ) relata que era a mais velha entre os pares e sua equipe, de 27 pessoas, formada por pessoas bem mais jovens. A consciência dessa realidade levou-a a conjecturar que em breve teria que desistir da carreira em organizações: “(...) eu quero mais uns dez anos de empresa, no máximo, e depois pensar numa carreira solo, porque eu não vejo futuro prá mim numa empresa, com mais de 50, 55 anos". Em outras palavras, a preocupação de R14 mostra a sobreposição da norma de idade sobre a ideia de "vida útil" no mundo corporativo. Faz sentido a preocupação de R14, a partir dos resultados encontrados por França et al. (2017), em que os trabalhadores mais jovens demonstram atitudes mais negativas com relação ao envelhecimento no ambiente organizacional.

Para finalizar, alguns aspectos foram realçados nesta categoria de análise: apenas três mulheres reportavam-se a superiores do sexo feminino; todos os respondentes tinham homens mais jovens como pares e na equipe, e à exceção de um, todos os donos de empresa eram do sexo masculino. Essa evidência sugere que a mulher em cargo gerencial, potencialmente, está mais sujeita aos estereótipos de idade, pois pertence a um grupo de minoria nas organizações, conjuntamente com o estereótipo voltado às mulheres, como um grupo social. A segunda categoria analítica discutida foi denominada Ruptura pelo Corte.

\subsection{A RUPTURA PELO CORTE}

O corte, apresentado como justificativa por todos os respondentes homens deste estudo e metade das respondentes mulheres, é visto de forma negativa por todos eles, 
embora pareça, em alguns momentos, uma explicação psicologicamente confortável para quem foi alvo dele, pois não demanda maiores explicações e justificativas, para si e para os outros.

O corte, neste contexto, também demonstra ser uma justificativa adequada em função da isenção de culpados. O corte pode ser conjuntural ou estrutural (CALDAS, 2000), sendo o primeiro tipo uma resposta direta à crise econômica ou queda de demanda, e o segundo relacionado à tentativa de se aumentar a competitividade da empresa. Algumas empresas cortam pessoas apoiando-se no discurso de prevenção, em vez de apoar-se no discurso de saneamento, que era utilizado no passado (CALDAS, 2000). Nessa linha de raciocínio, Kim e Mo (2014) constataram que, na Coreia do Sul, os trabalhadores idosos são as primeiras vítimas da reestruturação do emprego e dos regulamentos de limite de idade durante o recrutamento.

Não apenas as mudanças estruturais vitimam os trabalhadores mais velhos. Dados de uma pesquisa realizada no Brasil por Stocker et al. (2018) indicam que o compromisso, o histórico de desempenho e a confiança têm maior impacto na decisão de demissão, enquanto a relação interpessoal, o potencial de crescimento e a experiência profissional formam um grupo de critérios secundários. A pesquisa foi realizada com 385 gestores que tomam decisões sobre demissão. A maioria é de homens (51,7\%), com idades entre 25 e 44 anos (74,03\%), e até 10 anos de experiência profissional $(55,84 \%)$. Esses resultados fornecem evidência empírica de que trabalhadores mais velhos, em geral os mais experientes, tornam-se alvo de demissão, uma vez que a experiência profissional aparece na última posição na hierarquia dos critérios para decisão de demissão. Esse fato pode refletir preconceitos e estereótipos dos gestores mais jovens em relação ao trabalhador mais velho.

Considerando os resultados deste estudo, o corte, na perspectiva da organização, aparece como uma solução confortável para quem efetua o desligamento, em função da impessoalidade do fenômeno, que exime o gestor ou profissional da área de Recursos Humanos da responsabilidade de oferecer um feedback ao profissional que está sendo desligado. 'A empresa está passando por um processo de reestruturação' é o início de um discurso que, em geral, termina no desligamento de funcionários, e, da forma como o raciocínio é exposto, é uma decisão que não parte de quem a anuncia e isenta eventuais responsáveis pelo corte.

No entanto, para quem é vítima do corte, uma situação de dissonância pode surgir devido ao sentimento de que o motivo pode estar mais focado na empresa do que na pessoa. Nesse momento, existe uma percepção de que, quando o profissional é efetivamente bom, a empresa o realoca em outra área; embora isso não seja dito, o sentimento causa certo desconforto em quem passa por esta experiência. Além disso, o gestor que é vítima do corte, muitas vezes já utilizou essa justificativa ao desligar membros de sua equipe e, portanto, sabe que se trata de um estratagema. No âmbito pessoal, o gerente vivencia situação peculiar e ambígua, pois participa da condução de reestruturações e é, ao mesmo tempo, um dos segmentos mais atingidos por essas estratégias (MELO, 2002). Isso talvez explique os sentimentos contraditórios que, em geral, a justificativa do corte provoca nos entrevistados que dele foram vítimas.

O fenômeno do corte parece conter outras implicações, uma vez que todos os profissionais entrevistados, que foram vitimados por ele, eram mais velhos que seus pares e superiores; e, na maior parte dos casos, o corte atingiu no mesmo momento outros profissionais, colegas de trabalho, na mesma situação dos envolvidos, sugerindo a existência

RGO - Revista Gestão Organizacional, Chapecó, v. 13, n. 2, p. 188-206, maio/ago. 2020. 
de uma espécie de "saneamento etário" nas organizações. Nesse sentido, R7 comenta sobre o alvo das demissões “(...) comigo foram mais uns 10 gerentes, e a maioria dos antigos!".

Neste estudo, todos os respondentes homens e metade das mulheres foram cortados de suas últimas empresas. Das mulheres, as que não foram vítimas de corte solicitaram seu desligamento ou foram desligadas, alegando dificuldades de relacionamento com seus superiores por terem visões diferentes (R8), transtornos ligados à falta de ética da CEO, que a obrigava a assinar documentos duvidosos (R17), ou falta de reconhecimento e clareza da função (R11). Essas mulheres assumiram um papel ativo de resistência, principalmente ao comando masculino, e mostraram firmeza na defesa de suas convicções, mesmo que tenham tido que deixar o emprego.

A Figura 1 mostra a estrutura analítica dos resultados. Sua lógica subjacente permite inferir que o etarismo no contexto organizacional foi provocado pelos estereótipos, preconceitos e discriminação aos trabalhadores mais velhos, e pelas normas etárias implícitas. Esses fatores foram determinantes para a ocorrência de um tipo de saneamento de profissionais acima de 45 anos, que foi materializado por práticas de cortes de efetivo e substituição por empregados mais jovens. As organizações procuram elaborar justificativas plausíveis para si (ou seja, não etaristas), em torno da necessidade do corte, para promover mudanças estruturais de ajuste às demandas do mercado. Do lado individual, os respondentes percebiam alguns indícios para futura demissão, como os salários mais altos, o tempo de casa e os benefícios mais elevados. Comparativamente a outros estereótipos etários, há pequena evidência da validade desse estereótipo largamente aceito (POSTHUMA; CAMPION, 2009). Ser mais velho e custar caro para a empresa soam como uma justificativa econômica confortável e, de certo modo, concebível, pois tira do trabalhador mais velho qualquer responsabilidade pela demissão.

Estudos apontam que profissionais mais velhos estão sujeitos a enfrentar obstáculos nos diferentes processos de gestão de pessoas (PERRY; PARLAMIS, 2006; TRUXILLO et al., 2018), e não apenas no desligamento, como foi o foco desta pesquisa.

Figura 1. Estrutura analítica dos resultados

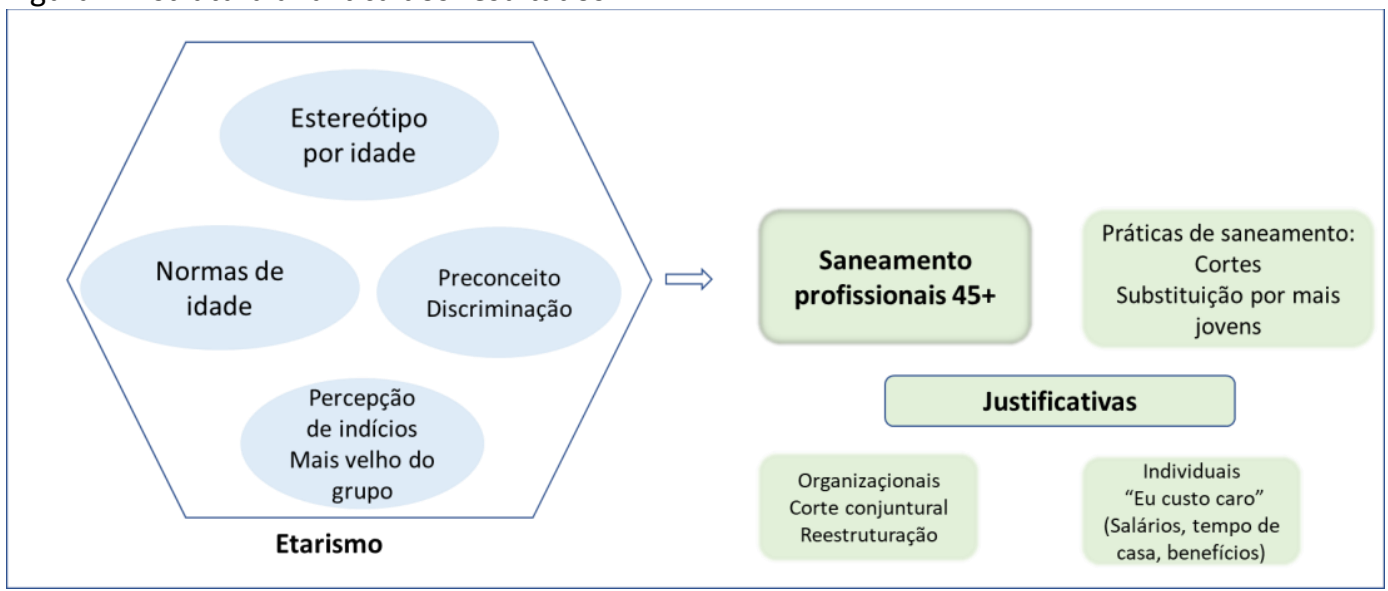

Fonte: elaborado pelas autoras

\section{CONSIDERAÇÕES FINAIS}

O estudo teve por objetivo compreender como o etarismo se manifesta antes e depois do desligamento do último emprego, na ótica de gerentes desempregados com idade acima de 45 anos. Os resultados da pesquisa indicam que estereótipos (atribuição de características 
negativas) e preconceitos (sentimentos negativos) de superiores, pares e colegas, em geral mais novos, estão subjacentes às decisões de demissão de gestores mais velhos, e fomentam uma prática discriminatória (ação) individual ou institucionalizada.

A pesquisa contribui para o avanço da literatura em três principais aspectos. Primeiro, a parte empírica, apoiada na percepção de gestores demitidos, com idade acima de 45 anos, preenche uma lacuna na literatura, e é fundamental para compreender a vivência do fenômeno do etarismo nas organizações sob a ótica do sujeito vitimado. Os dados mostraram que os estereótipos de idade, o preconceito e a discriminação, juntos, compõem o etarismo. Há evidências de que a percepção etarista dos tomadores de decisão sobre a demissão dos trabalhadores mais velhos sustenta as normas de idade das organizações. Em conjunto, verificamos que o etarismo e as normas de idade - regra implícita que determina a idade ideal para a ocupação de cargos - estão subjacentes aos argumentos gerenciais que sustentam uma justificativa plausível para o saneamento etário, sob a alegação racional de reestruturações organizacionais e o custo elevado dos trabalhadores mais velhos.

O segundo aspecto é a percepção relativa da demografia etária do grupo de trabalho - não necessariamente a idade real - e a existência de normas de idade favorecem a autocategorização dos respondentes em um grupo social com menos recursos e privilégios que o grupo formado por trabalhadores mais novos. Observamos nos achados o vigor das dimensões emocional e avaliativa da Teoria da Identidade Social (TAJFEL, 1982) nessa reconstrução de identidade. Perceber que se faz parte do exogrupo, aquele dos mais velhos, não é nada confortável. Entendemos que algumas atitudes de valorização desse grupo, em comentários como 'os mais velhos são mais maduros' e 'possuem maior conhecimento em relação aos mais jovens', foram sinalizações de estratégias psicológicas para justificar a "passagem" do antigo endogrupo (não velhos) para o exogrupo (velhos). Se, para os gerentes, essa passagem, não raro, é forçada repentinamente pelo rito do corte, para as organizações pode ser uma estratégia de "saneamento etário", justificada confortavelmente por fatores exógenos (concorrência, economia, fusão/aquisição, entre outras) e, por isso, requer poucas explicações, sem maiores detalhes, evitando assim eventuais conflitos, e servindo como justificativa plausível para o próprio funcionário. Acreditamos que essa percepção da demografia contribui para a literatura de demografia relacional (TSUI; EGAN; O'REILLY, 1992) nos grupos de trabalho, pois a percepção de similaridade e dissimilaridade etária é contingente ao envelhecimento do indivíduo, diferindo de outras categorias demográficas, como sexo e raça.

Finalmente, entender o etarismo na ótica de gestores mais velhos demitidos coloca em tela uma situação que tende a se agravar em períodos de baixo crescimento econômico, de reestruturação, em que o corte é aclamado como uma estratégia inevitável, vitimando os trabalhadores mais velhos. Essa lógica indica que a experiência profissional acumulada em anos de trabalho gerencial é um aspecto pouco valorizado nas decisões de demissão. Isto é corroborado pela pesquisa de Stocker et al. (2018), que apresentaram a visão de gestores que tomam decisões sobre demissões. Entretanto, o estudo não revela a razão dessas decisões. 0 resultado da presente pesquisa indica que a forte presença do etarismo contribui para entender os fatores subjacentes à desvalorização da experiência profissional.

Estudos internacionais mostram que os estereótipos de idade são prejudiciais a profissionais mais velhos, que enfrentam mais obstáculos do que os jovens no mercado de trabalho (POSTHUMA; CAMPION, 2009), seja para conseguir um emprego, seja para desenvolver-se na organização. Os resultados desta pesquisa indicam a interseccionalidade 
entre idade e gênero, um desafio adicional para a permanência das mulheres gestoras nas organizações.

A discriminação etária no ambiente de trabalho verificada na pesquisa assumiu uma forma dual (STYPINSKA; TUREK, 2017). A forma rígida (hard) espelha os tipos de comportamentos legalmente proibidos - mas que ocorrem de fato dentro de organizações, como a existência de um limite de idade para a contratação de pessoas para determinado cargo, demissão, ou aposentadoria compulsória. Outra forma é a suave (soft) que corresponde àquelas ocorrências que não estão inscritas no sistema legal, e ocorrem predominantemente na esfera interpessoal, mas podem ter consequências negativas para os trabalhadores mais velhos. Os preconceitos percebidos e a ação discriminatória conjunta hard e soft - ambos são manifestações dos estereótipos e formam a base do etarismo.

Os dados evidenciam que o etarismo parece embasar um estratagema de saneamento utilizado pelas organizações. Retomando as recomendações de Lawrence (2004), os efeitos da idade não mostram um duplo caminho, mas apenas um: os empregados precisam adaptarse às definições de idade de suas organizações. Ou seja, as normas de idade somente direcionam o comportamento organizacional e não no sentido contrário.

Afinal, quais são as perspectivas para uma população economicamente ativa em crescente envelhecimento? Uma alternativa para minimizar esses problemas seria a revisão do desenho organizacional com foco na diversidade etária, conforme sugerido por Lawrence (2004) e programas de valorização interna para funcionários de todas as idades. Ademais, incentivos governamentais para diminuir gastos com encargos e benefícios podem contribuir para que haja menos etarismo nas empresas, além de políticas públicas que favoreçam a entrada de pessoas mais velhas nas empresas, bem como sua permanência, pois o envelhecimento é, cada vez mais, uma questão social no Brasil. O Banco Mundial (2011) aponta que programas de treinamento específicos podem ser eficazes para suavizar ou anular o declínio associado à idade, na habilidade de aprender novas técnicas. Nesse sentido, no futuro, as firmas precisarão expandir os programas de treinamento, para investir na aprendizagem ao longo da vida e reorientar os programas para atender às necessidades dos trabalhadores mais velhos. Nessa mesma linha, o UNFPA (2011) sugere algumas ações prioritárias para maximizar as oportunidades de populações em envelhecimento: flexibilidade de horários de trabalho, aprendizagem continuada ao longo da vida e oportunidades de requalificação devem ser promovidas para facilitar a integração no mercado de trabalho das atuais gerações de idosos.

Os resultados desta pesquisa têm implicações para políticas e programas sociais no ambiente de trabalho. Uma força de trabalho cada vez mais longeva, fruto do envelhecimento acelerado no Brasil, significará uma intensificação de contatos intergeracionais nos grupos de trabalho. Essa convivência tanto poderá ser uma oportunidade de aprendizagem como uma fonte de conflito, dependendo de práticas organizacionais voltadas à gestão da idade.

Algumas limitações precisam ser consideradas. Primeira, embora cuidados tenham sido tomados, os 18 participantes da pesquisa foram selecionados por conveniência a partir da rede profissional das autoras. Este fato pode ter levado a um viés na percepção das razões do desligamento. Segunda limitação: destacamos que o perfil relativamente homogêneo dos respondentes também é uma limitação. A maioria (88\%) é ou foi casada, e possui filhos. Nenhum negro ou negra participou da pesquisa. Quanto à orientação sexual, não foi perguntado ao participante, mas as evidências apontam para um perfil heterossexual. Condizente com a função gerencial, $72 \%$ dos participantes realizaram curso de pós-graduação. Assim, os resultados apresentados não permitem sua extrapolação para outros grupos sociais. 
No decorrer deste estudo identificamos lacunas que sugerem futuras pesquisas. Estudo relevante seria pesquisar gestores contratantes e/ou profissionais de recursos humanos, a fim de entender a influência desses profissionais nas atitudes e práticas etaristas no ambiente organizacional. Tendo em vista os poucos estudos sobre o tema no Brasil, os resultados desta pesquisa poderiam subsidiar o desenvolvimento de escala para mensurar o etarismo e explorar as práticas organizacionais voltadas à idade (gestão da idade), na perspectiva dos trabalhadores mais velhos.

\section{REFERÊNCIAS}

AMORIM, W. A. C.; FEVORINI, F.B.; MELO, A. F. S.; TAVARES, A. S. O mercado de trabalho para trabalhadores com 50 anos ou mais no Brasil. Informações FIPE: Temas de Economia Aplicada, p. 9-24, dez.2016. Recuperado de https://downloads.fipe.org.br/publicacoes/bif/bif435-9-24.pdf

AYALON, C.; TESCH-RÖMER, C. Introduction to the Section: Ageism - Concept and Origins. In: AYALON, C.; TESCH-RÖMER (Eds.). Contemporary Perspectives on Ageism. Cham, $\mathrm{CH}$ : Springer International Publishing, 2018, p.1-10.

BANCO MUNDIAL. Envelhecendo em um Brasil mais velho: implicações do envelhecimento populacional para o crescimento econômico, a redução da pobreza, as finanças públicas e prestação de serviços. Brasil: Banco Mundial, 2011.

BUTLER, R. N. Ageism: another form of bigotry. The Gerontologist, Oxford, v. 9, n. 4 (Part 1), p. 243-246, 1969. DOI:10.1093/geront/9.4_Part_1.243

BUTLER, R. N. Why survive? Being old in America. New York: Harper \& Row, 1975.

BUTLER, R. N. Ageism: a foreword. Journal of Social Issues, Hoboken, v. 36, n. 2, p. 8-11, 1980. DOI:10.1111/j.1540-4560.1980.tb02018.x

Byrne, D. E. The attraction paradigm. New York: Academic Press, 1971.

BYTHEWAY, B. Ageism (Rethinking ageing). Buckingham: Open University Press, 1995.

CALDAS, M. P. Demissão: causas, efeitos e alternativas para empresa e indivíduo. São Paulo: Atlas, 2000.

CAMARANO, A. A.; KANSO, S.; FERNANDES, D. Menos jovens e mais idosos no mercado de trabalho? In: CAMARANO, A. A. (Org.). Novo regime demográfico: uma nova relação entre população e desenvolvimento? Rio de Janeiro: IPEA, 2014. p. 377-406.

CARY, L. A.; CHASTEEN, A. L.; REMEDIOS, J. The ambivalent ageism scale: developing and validating a scale to measure benevolent and hostile ageism. The Gerontologist, Oxford, v. 57, n. 2, p. 27-36, 2017. DOI:10.1093/geront/gnw118.

CEPELLOS, V. M.; TONELLI, M. J.; ARANHA, F.; PEREIRA FILHO, J. L. Envelhecimento nas organizações: preconceito ou tendência? GVexecutivo, São Paulo, v. 12, n.2, p. 124-127, jul./dez., 2013. 
CRESWELL, J. W. Research design: qualitative, quantitative and mixed methods approaches (4th ed.). Thousand Oaks, CA: Sage Publications, Inc., 2014.

FINEMAN, S. Age Matters. Organizational Studies, Thousand Oaks, v. 35, n. 11, p. 17191723, 2014. DOI:10.1177/0170840614553771.

FINEMAN, S. Organizing Age. Oxford (UK): Oxford University Press, 2011.

FISKE, S. T. Intent and ordinary bias: unintended thought and social motivation create casual prejudice. Social Justice Research, Berlin, v.17, p. 117-127, 2004. DOI:10.1023

FISKE, S. T.; TAYLOR, S. E. Social cognition. New York: McGraw-Hill, 1991.

FRANÇA, L. H. F. P.; SIQUEIRA-BRITO, A. R.;VALENTINI, F.; VASQUES-MENEZES, I.; TORRES, C. V. Ageismo no contexto organizacional: a percepção de trabalhadores brasileiros. Revista Brasileira de Geriatria e Gerontologia,Rio de Janeiro, v. 20, n. 6, p. 765-777, 2017. DOI:10.1590/1981-22562017020.170052.

FUNDO DE POPULAÇÃO DAS NAÇÕES UNIDAS (UNFPA). Envelhecimento no Século XXI: Celebração e desafio. Nova York. 2012.

GOLDANI, A. M. Desafios do "preconceito etário" no Brasil. Educação \& Sociedade, Campinas, v. 31, n. 111, p. 411-434, 2010.

INSTITUTO BRASILEIRO DE GEOGRAFIA E ESTATÍSTICA. Projeções da população: Brasil e Unidades da Federação, 2013. Disponível em

ftp://ftp.ibge.gov.br/Projecao_da_Populacao/Projecao_da_Populacao_2013/srm40_projeca o_da_populacao.pdf.

KARPINSKA, K.; HENKENS, K.; SCHIPPERS, J. Hiring retirees: impact of age norms and stereotypes. Journal of Managerial Psychology, v. 28, n. 7/8, p. 886-906, 2013. DOI: 10.1108/JMP-07-2013-0223.

KIM, D. S.; MO, S. H. Stereotypical beliefs on old korean workers. Ageing International, Berlin, v. 39, n. 4, p. 385-402, 2014. DOI:10.1007/s12126-014-9200-4.

LAWRENCE, B. S. How old you are may depend on where you work. In: CHOWDHURY, S. (Ed.) Next generation business handbook: New strategies from tomorrow's thought leaders. Hoboken, NJ: John Wiley \& Sons, 2004. p. 986-1006.

LOCATELLI, P. A. P. C.; FONTOURA, D. S. Envelhecimento populacional e os estudos em administração. Gestão e Sociedade, Belo Horizonte, v. 7, n. 17, p. 273-300, 2013. DOI:10.21171/ges.v7i17.1689.

MACDONALD, J. L.; LEVY, S. R. Ageism in the workplace: the role of psychosocial factors in predicting job satisfaction, commitment, and engagement. Journal of Social Issues, Hoboken, v. 72, n. 1, p. 169-190, 2016. DOI:10.1111/josi.12161. 
MAGNARELLI, J.; STRICKER, L.; FRY, D.; TAHMASEB-McCONATHA, J.; SCHNELL, F. Ageism in the Workplace: Ageing in the Age of Intolerance. 2020. Disponível em:

https://digitalcommons.wcupa.edu/psych_stuwork/6. Acesso em 20 maio 2020.

MELO, M. C. O. L. Gerência feminina nos setores industrial e bancário: o conservador internalizado versus o moderno em construção. In: Assembléia do Conselho LatinoAmericano de Escolas de Administração - CLADEA, 37., 2002, Porto Alegre. Anais ... Porto Alegre: UFRGS, 2002. CD-ROM.

MILES, M. B.; HUBERMAN, A. M.; SALDAÑA, J. Qualitative data analysis: A methods sourcebook (3rd ed.).Thousand Oaks, CA: Sage Publications, 2014.

NELSON, T. D. The age of ageism. Journal of Social Issues, Hoboken, v. 72, n. 1, p. 191-198, 2016. DOI:10.1111/josi.12162.

NELSON, T. D. (Ed.) Handbook of prejudice, stereotype and discrimination. New York: Taylor \& Francis Group, 2009.

NELSON, T. D. (Ed.). Ageism: Stereotyping and prejudice against older persons. Cambridge, MA: The MIT Press, 2004.

NG, T. W. H.; FELDMAN, D. C. A meta-analysis of the relationships of age and tenure with innovation-related behaviour. Journal of Occupational and Organizational Psychology, Leicester, v. 86, n. 4, p. 585-616, 2013. DOI:10.1111/joop.12031.

NORTH, M. S.; FISKE, S. T. An inconvenienced youth ? Ageism and its potential intergenerational roots. Psychological Bulletin, Washington, D.C., v. 138, n. 5, p. 982-997, 2012. DOI:10.1037/a0027843.

ORGANIZAÇÃO MUNDIAL DA SAÚDE. Definition of an older or elderly person. 2015. Disponível em: <http://www.who.int/healthinfo/survey/ageingdefnolder/en/>. Acesso em: 15 ago. 2018.

PALMORE, E. Ageism: Negative and positive. 2nd.ed. New York, NY: Springer Publishing Company, 1999.

PEREIRA, M. F. M. W. M. Um Estudo sobre o Etarismo nas Organizações. 2014. $128 \mathrm{f}$.

Dissertação (Mestrado em Administração) - Universidade Presbiteriana Mackenzie, São Paulo, 2014.

PERRY, E. L.; PARLAMIS, J. D. Age and ageism in organizations: a review and consideration of national culture. In: KONRAD, A.M.; PRASAD, P.; PRINGLE, J.K. (Eds.). Handbook of workplace diversity. London: Sage, 2006. p. 345-370.

POSTHUMA, R. A.; CAMPION, M. A. Age stereotypes in the workplace: common stereotypes, moderators, and future research directions. Journal of Management, Thousand Oaks, v. 35, n. 1, p. 158-188, 2009. DOI: 10.1177/0149206308318617.

POSTHUMA, R. A.; WAGSTAFF, M. F.; CAMPION, M. A. Age stereotypes and workplace age discrimination. In: BORMAN, W.C.; HEDGE, J.W.;. (Eds.). Oxford Handbook of Work and 
Aging. New York: Oxford University Press, 2012, p. 298-312. DOI: 10.1093/oxfordhb/9780195385052.013.0104.

SHORE, L. M.; CHUNG-HERRERA, B. G.; DEAN, M. A.; EHRHART, K. H.; JUNG, D. I.; RANDEL, A. E.; SINGH, G. I. Diversity in organizations: where are we and where are we going? Human Resource Management Review, London, v. 19, p. 117-133, 2009.

DOI:10.1016/j.hrmr.2008.10.004

STOCKER, F.; VILLAR, E. G.; ROGLIO, K.D.; ABIB, G. Dismissal: important criteria in managerial decision-making. RAE-Revista de Administração de Empresas, São Paulo, v. 58, v. 2, p. 116 129, 2018. DOI: http://dx.doi.org/10.1590/S0034-759020180202

STYPINSKA, J.; TUREK, K. Hard and soft age discrimination: the dual nature of workplace discrimination. European Journal of Ageing, Berlin, v. 14, n. 1, p. 49-61, 2017. DOI 10.1007/s10433-016-0407-y.

SWIFT, H. J.; ABRAMS, D.; LAMONT, R. A.; DRURY, L. The risks of ageism model: how ageism and negative attitudes toward age can be a barrier to active aging. Social Issues and Policy Review, Hoboken, v. 11, n. 1, p.195-231, 2016.

TAJFEL, H. Social Psychology of Intergroup Relations. Annual Reviews Psychology, Washington, D.C., v. 33, p. 1-39, 1982. DOI: 10.1146/annurev.ps.33.020182.000245.

THOMAS, R.; HARDY, C.; CUTCHER, L.; AINSWORTH, S. What's age got to do with it? On the critical analysis of age and organizations. Organization Studies, Thousand Oaks, v. 35, n. 11, p. 1569-1584, 2014. DOI: 10.1177/0170840614554363.

TSUI, A. S.; EGAN, T. D.; O’REILLY III. Being different: relational demography and organizational attachment. Administrative Science Quarterly, Thousand Oaks, v. 37, n. 4, p. 549-579. 1992. DOI:10.2307/2393472

TONELLI, M. J.; CEPELLOS, V. M.; LINS, J. (Coords.). Envelhecimento nas organizações e a gestão da idade (Relatório de Pesquisa). São Paulo: FGV/EAESP, 2018. Disponível em: <https://revistamelhor.com.br/wp-content/uploads/2018/04/PESQUISA-ENVELHECIMENTO.pdf>. Acesso em: 16 nov. 2018.

TONELLI, M. J.; LINS, J. L.; ARANHA FILHO, F. J. E. Envelhecimento da força de trabalho no Brasil. PWC, São Paulo, mar. 2013. Disponível em:

<http://www.pwc.com.br/pt_BR/br/publicacoes/servicos/assets/consultoria-negocios/pesqenv-pwc-fgv.pdf>. Acesso em: 1 jun. 2013.

TRUXILLO, D. M.; FINKELSTEIN, L. M.; PYTLOVANY, A. C.; JENKINS, J. S. Age Discrimination at Work: A Review of the Research and Recommendations for the Future. In: COLELLA, A. J.; KING, E. B. (Eds.). The Oxford Handbook of Workplace Discrimination. Oxford University Press, 2018. P. 1-26. DOI: 10.1093/oxfordhb/9780199363643.013.10.

VASCONCELOS, A. F. Organizations' workforce demographic age preferences: multiple case studies from Brazil. Journal of Management Development, Bingley, v. 35, n. 3, p. 406-427, 2016. DOI: 10.1108/JMD-08-2015-0111. 